dition of semi-consciousness persisted for a quarter of an hour. Upon his recovery, and afterwards, he was unable to reeall anything which had happened during the attack and for some hours preceding the paroxysm.

The author makes clear the distinction between these retrograde amnesias and the cases where the crisis is preceded by vertigo or delirium; and there should also be a distinetion from the post epileptic confusion, which are so common in eases in which aleohol and tratumatism play a part.

The medico-legal aspect of this state of forgetfulness is of obvious importance.

Gaz. Hebd. de Médl. et de Chie., Mareh I8, ı897:

\title{
The Tendon Reflexes in the Post Epileptic State.
}

G. Pieraccini in studying the belnavior of the tendon reflexes during and after epileptic convulsions, came to the following results: Inmediately after a convulsive attack in the period of coma, the tendon reflexes are almost abolished, or at least decidedly diminished. After an interval of 5 minutes to half an hour they reappear, feeble at first, then slowly increase until the patient is completely over the attack when the reflexes are found slightly increased. The diminution of the reflexes is proportional to the duration and intensity of the atrack. In even lateral convulsionis the abolition of the reflexes is linlited to the affected side. - Settinana Med. dello Sperimenale, No. 32, I896.

Constant Signs of Epilepsy.

W. C. K.

MM. Mairet and Vires read before the Academic de Médecine (Medical Week, Feb. 5, 1897), a paper on epilepsy, in which the atthors say it has been their endeavor to find constant signs of that disease, whose existence would permit of the certain diagnosis of the epileptic nature of an attack, whether of convulsive or larval epilepsy. This is especially important since epilepsy of the convulsive form may be simulated so well as to make it difficult for the most careful examination to detect the imposition. The authors from study of a large number of cases have reached the following conclusions:

Even a single attack of epilepsy is associated with an increase in the nitrogen and phosphates excreted.

The course of the general temperature is characteristic. being lower than normal during the convulsive period and during or following sleep, with an increase upon awakening and a gradual rise to the normal. The urine is hypotoxic after the attack.

During the periods between the paroxysms the urine is hypotoxic also. The fatal dose of the urine of a healthy person varies between 45 and 80 cubic centimetres, whereas that of the epileptic is between 150 and 250 cubic eentimetres.

The urine of larval epilepsy is constantly liypotoxic, the fatal dose ranging between 150 and 480 cubic centimetres.

This constant hypotoxicity in epilepsy is therefore an importanc, permanent sign from a medieo-legal point of view, especially as it may be utilized for a diagnosis of the obseure larval form of epilepsy.

J. K. MITCHELI.

PSYCHIATRY.

\section{Essential Acrophobia.}

Acrophobia (fear of high places) in a degree scarcely to be designated as pathologieal, is very frequent in nervous and timid people. As a marked or prominent symptom in the more pronounced cases of neurasthenia it is far from rare, but entirely dissociated from other nervous nianifestations it is very uneommon.

Gelieanu (Jour. de Méd. de Paris, Oet. 4, I896) reports such a case 
in the person of a young Russian. If the dates given in the paper are correct, the trouble began when the patient was only ro years old, and without apparent cause. There was a neuropathic family history, but the first attack occurred on a cliff where the boy had been accustomed to go daily. While regarding the declivity, he was suddenly taken with vertigo, weakness and an agonizing oppression. With difficulty he regained the dwelling, which was near at hand, and was obliged to go to bed. The next day he could laugh at his fears and had no more attacks for a year. Then he was again seized with the unaccountable fainting terror and for the remainder of the summer was unable to walk on any elevation, even a hill. Seated in a carriage he had no trouble. Following this time he lived for six years in a flat country and was perfectly well. He then had occasion to return to the scene of his first attack when the trouble immediately returned, and was more severe than ever. He was now as bad in a carriage as on foot, and even to look out of the window of a house situated on a bluff hrought on the insupportable agony with a feeling of impending death. For two years after this he was the subject of this abnormal fear. Looking at a photograph or painting of mountains would bring on an attack. He began, too, to be nervous and apprehensive in a crown and felt comfortable only at home or on a plain. A combination of tonics and sedatives greatly improved his condition, but there is no assurance against a relapse.

Patrick (Chicago).

A Study of the Blood In General Paralysis. By J. A. Capps. American Journal of the Medical Sciences, June 18, 1896.

The conclusions based on the observation of 19 cases are:

I. The hæmoglobin and red corpusales are always diminished.

2. The specific gravity falls slightly below the normal.

3. Most cases show a slight leucocytosis, amounting on an average to about 22 per cent. above the normal. Early cases may have no leucocytosis whatever.

4. In the differential count a decrease is found in the lymphoyts along with a marked increase in the large mononuclear cells. The essiuophiles in a few cases are very numerous.

In convulsions and apoplectiform attacks ( $r$ ) the red corpuscles and hrmoglobin are usually increased at the time of a convulsion. During an apoplectic attack of long duration they are both somewhat diminished.

2. The specific gravity is variable, sometimes increasing, sometimes diminishing, at the time of an attack.

3. There is a leucocytosis after convulsions and apoplectic attacks, which is as sudden as it is usually pronounced. It certainly does not appear until within a very short time preceding the convulsion, probably not before it actually takes place.

4. The degree of leucocytosis and the period of its continuousness, as a rule, vary directly with the length and severity of the attack.

5. In the production of the leucocytosis the large mononuclar cells are increased relatively more than any other variety.

6 . The fact that after convulsions and apoplectic attacks in general paralysis there is not only an increase in the number of white cells, but a change in their character, as shown by the differential count, and at times abnormal cells appear, is an argument against the theory that leucocytosis is merely a change in the distribution of the white corpuscles.

SHIVELY.

\section{Disturbance of Sensibility in Melancholya}

Dr. Pierre Dheur finds (Thése de Paris, 1896 , No. 62) that disturbances of sensation are the rule in the course of melancholia, whether the form of the disease be the depressed, agitated or dull type. 